Biblioteca Universitaria

ISSN: 0187-750X

public@dgb.unam.mx

Universidad Nacional Autónoma de México

México

Villarello Reza, Rosamaría

A 100 años de la fundación de la UNAM: un sumario de la historia de su Sistema Bibliotecario

Biblioteca Universitaria, vol. 14, núm. 2, julio-diciembre, 2011, pp. 123-144

Universidad Nacional Autónoma de México

Distrito Federal, México

Disponible en: http://www.redalyc.org/articulo.oa?id=28521613002

Cómo citar el artículo

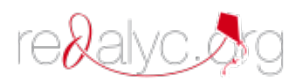

- Número completo

- Más información del artículo

Página de la revista en redalyc.org

Sistema de Información Científica

Red de Revistas Científicas de América Latina, el Caribe, España y Portugal

Proyecto académico sin fines de lucro, desarrollado bajo la iniciativa de acceso abierto 


\title{
A 100 años de la fundación de la UNAM:
}

uin sumario de la historia de su. Sistema Bibliotecario

\author{
100 Years of the founding of UNAM: a brief history of its library system
}

\section{Rosamaría Villarello Reza*}

\section{RESUInEn}

Con motivo de los 100 años de la Universidad Nacional Autónoma de México, se hace un recorrido de sus antecedentes desde la Real Universidad de México, su fundación en 1910 y por diferentes momentos como el de su autonomía, la creación de la Ciudad Universitaria y los años posteriores hasta 2010. En este contexto, se inscribe el sumario de la historia del Sistema Bibliotecario de la UNAM. La creación de la Dirección General de Bibliotecas (DGB) marca un nuevo período de desarrollo de las bibliotecas universitarias, que va a ser particularmente destacado por el trabajo y las iniciativas de cada uno de los directores que han estado al frente de ella, y por su personal bibliotecario.

Palabras clave: unam, sistema bibliotecario, bibliotecas universitarias, historia de las bibliotecas, Dirección General de Bibliotecas, México.

\section{Abstract}

To mark the 100 years of the National Autonomous University of Mexico, this paper presents a tour of its history, from the Royal University of Mexico, its founding in 1910 and for different times, such as when it received its autonomy, the creation of the University City and beyond, to 2010. In this context, the brief history of the UNAM Library System is inserted. The creation of the General Directorate of Libraries marks a new development period for academic libraries that will be particularly highlighted by the work and initiatives of each of the directors who have been leading it, as well as its library staff.

KEYWORDS: 100 years of UNAM; historical summary; library system; background, founding and development.

\footnotetext{
Secretaría de Desarrollo Institucional de la UNAM. Torre de Rectoría, $8^{\circ}$ Piso, Circuito Interior, C.U., C.P. 04510, México D.F., México. Correo electrónico: rosamar3113@gmail.com.

La autora agradece a la licenciada en Bibliotecología, Acacia Mijangos Nolasco por su colaboración para la localización de bibliografía. Técnica Académica de la Dirección General de Bibliotecas, correo electrónico: acacia_mijangos@hotmail.com y a Julio Zetter Leal por sus comentarios y observaciones al presente artículo.
} 
A 100 años de la fundación de la UNAM: un sumario de la historia de su Sistema Bibliotecario

"La enseñanza superior no puede tener, como no tiene la ciencia, otra ley que el método...la Universidad Nacional... será la encargada de dictar las leyes propias, las reglas propias de su dirección científica... será una Universidad de Estado.... Justo Sierra, 1910.

"Con orgullo y satisfacción, podemos decirle a nuestro fundador, iMisión cumplida!" José Narro Robles, 2010.

\section{Introducción}

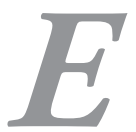
I presente artículo es un sumario de la abundante y rica historia de la formación de las bibliotecas de la Universidad Nacional Autónoma de México. La intención es dar a los lectores de Biblioteca Universitaria un panorama general de los esfuerzos desplegados por esa institución en el transcurso de estos cien años; así mismo, revisar el entorno nacional en que han surgido, pues sin la voluntad política del Estado y de sus representantes no hubiese sido posible iniciar lo que ahora es un gran Sistema Bibliotecario. Como todo proceso histórico, el proyecto original se ha ido transformando en la medida del desarrollo de nuestro país, impulsado por la propia sociedad.

La educación superior, como una prioridad de la Revolución mexicana, es un concepto integral en el cual las bibliotecas son imprescindibles. De ello dan cuenta todos aquellos personajes que se preocuparon para que se fundara la Universidad Nacional, como Justo Sierra, y posteriormente José Vasconcelos al lograr su autonomía y avance al ritmo del conocimiento en el mundo. Cada rector, cada trabajador de las bibliotecas y casi todos los gobiernos de la República han contribuido desde su ámbito de competencia.

Así se formó la Ciudad Universitaria y sus campi y la institución ha podido crecer en la enseñanza, la docencia, la investigación y la extensión de la cultura. Dentro de los servicios de apoyo, los servicios bibliotecarios han tenido un crecimiento impresionante y se han ido adaptando a los cambios, desde la existencia del libro impreso, los materiales hemerográficos, las bases de datos, la información científica y técnica, hasta los documentos electrónicos y la biblioteca digital. Por supuesto que la UNAM no ha estado exenta de los vaivenes políticos y de los problemas nacionales e internacionales, que han repercutido de una forma u otra en sus programas, pero no por ello ha dejado de cumplir con su misión.

Autoridades, académicos y personal administrativo han sido los responsables del Sistema Bibliotecario. La cada vez mayor preparación del personal bibliotecario y la profesionalización de los servicios, gracias a las instancias académicas que los han ido formando y capacitando, hoy han hecho posible contar con uno de los mejores equipos humanos y consolidar a la UNAM también en este campo como "Universidad de la Nación".

Los retos del siglo xxı han sido enfrentados con entereza por los rectores, que han puesto en los mejores niveles internacionales a la UNAM, extendiendo su prestigio a todo el mundo. Juan Ramón de la Fuente y José Narro se han nutrido de la labor de sus antecesores y han emprendido la misión educativa universitaria conforme a los nuevos tiempos, sobre todo para mantener a una institución pública de tales proporciones, a cien años de su fundación, en el siglo XXI.

Al doctor José Narro, quien presidió los festejos del Centenario, y a toda la comunidad universitaria que prestamos nuestros servicios en la UNAM, correspondieron el honor de participar de una forma u otra en ellos. En especial, nos sentimos gratificados los que nos ha tocado vivir entre libros, lecturas y teniendo un espacio de trabajo en la emblemática Biblioteca Central (BC).

La historia de las bibliotecas universitarias es de una gran riqueza y hay, por fortuna, una rica bibliografía elaborada por especialistas en la materia. No obstante, para los propósitos de este artículo, fue prácticamente imposible abocarnos a una más completa reseña. Tampoco fue el propósito abordar los aspectos técnicos, pues éstos rebasan el objetivo central. 
Por la importancia del tema, y porque necesitamos una memoria histórica de las bibliotecas, es que el siguiente paso será continuar con un proyecto que en alguna ocasión tuve oportunidad de expresar a la Dra. Silvia González Marín y que hoy reitero: hacer una historia compendiada, una enciclopedia de las bibliotecas y aprovechar todas las investigaciones que hay al respecto, así como redescubrir todas aquellas que aún permanecen fuera del alcance de los interesados en las bibliotecas, sobre todo ahora que la bibliotecología tiene ya un lugar en la historia de las ciencias. No es tarea fácil pero sí imperiosa.

En este artículo abarco desde los antecedentes coloniales, la fundación de la Universidad Nacional en la época vasconcelista, la creación de la Ciudad Universitaria, que desde mi punto de vista es cuando comenzó a consolidarse el Sistema Bibliotecario Universitario actual y su regulación con la posterior creación de la Dirección General de Bibliotecas, hasta 2010; así como los nuevos retos.

Sirva el presente para rendir un homenaje a nuestra Máxima Casa de Estudios y la creación de su Sistema Bibliotecario y su repercusión nacional.

A la memoria de la Dra. Silvia González Marín. Directora General de Bibliotecas 2000-2008 y Premio Sor Juana Inés de la Cruz 2010.

\section{Los inicios coloniales}

Los orígenes de las bibliotecas de México se remontan a la época de la colonización española. Los primeros libros que llegaron al Nuevo Mundo, sobre todo en los siglos XVI y XVII, fueron traídos por sacerdotes y clérigos, principalmente sobre la religión cristiana y de "virtud". No obstante, a pesar de estar prohibidos los libros de caballería, romance y "ficción" porque eran "un mal ejercicio para los indios", de acuerdo a las Cédulas Reales expedidas, entraron en grandes cantidades pasando por alto al Santo Oficio. ${ }^{1}$

Torre RevelLo, José. Lecturas Indianas: siglos XVI-XVIII. Bogotá, 1962. Separata de Thesaurus, Boletín del Instituto Caro y Cuervo, XVII, 1962. En: Millares Carlo, Agustín. Introducción a la Historia del libro y las bibliotecas..., 1988.

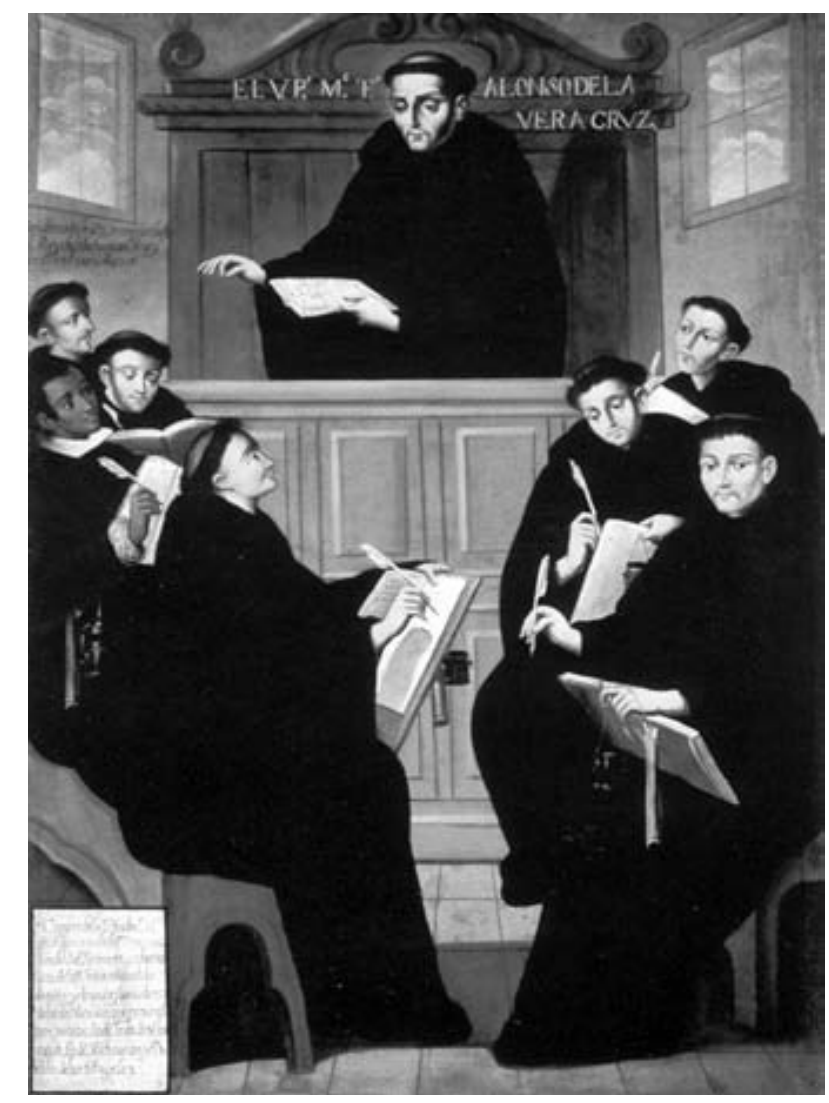

Aunque se tiene conocimiento de la existencia de bibliotecas indígenas anteriores a la conquista, las primeras bibliotecas del continente americano, de acuerdo a las fuentes de Millares, las fundó Fray Juan de Zumárraga (1528-1548) en Tenoxtitlán, capital de la Nueva España, así como la biblioteca "Turriana", conformada por Luis Antonio Torres. Ellas representan los primeros acervos que van a constituir, en gran parte, la biblioteca de la Real Universidad de México, fundada por la Cédula Real expedida en 1551 y convertida en Pontificia en 1595.

En el avanzado siglo xVII y en el xVIII la situación cambia y la proscripción se concentra en impedir que llegaran al país todas aquellas lecturas contrarias a mantener el sistema colonial y la religión católica. Sin embargo, el panorama se impregnó de aires libertarios y republicanos permeando tierras americanas: Voltaire, Montesquieu, Rousseau y demás pensadores liberales eran leídos profusamente, junto con otra literatura principalmente proveniente de España, a pesar de los castigos de la Santa Inquisición. Por lo que se refiere a los escri- 


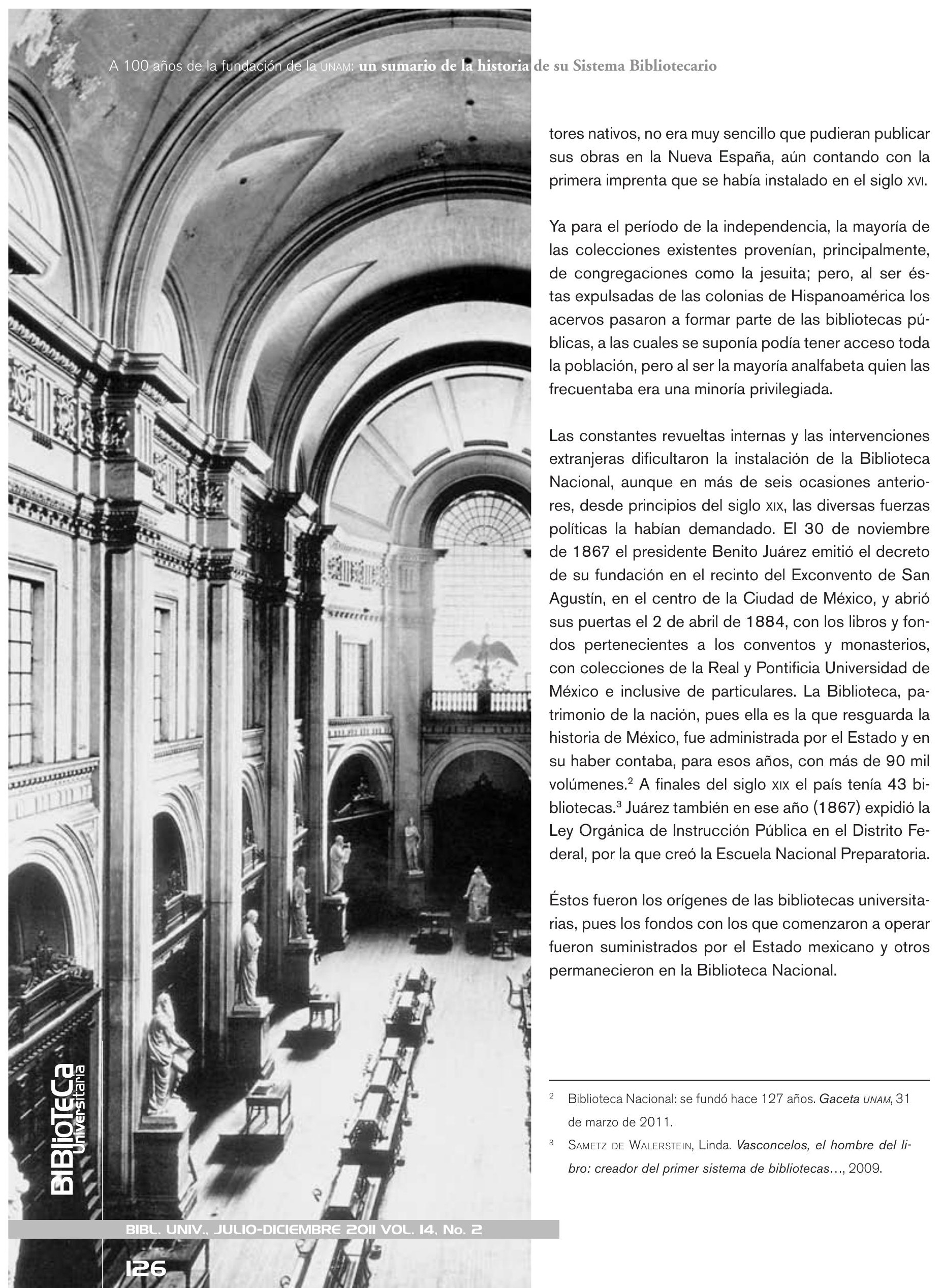




\section{Rosamaría Villarello Reza}

\section{La fundación de la Universidad Nacional}

Justo Sierra fue uno de los hombres que remontó con su obra educativa el régimen porfirista y el del movimiento revolucionario. Una de sus grandes preocupaciones, por ser él mismo un gran erudito, era la educación, por lo que siendo diputado ante el Congreso de la Unión lanzó el proyecto que fue aprobado de convertir a la educación primaria en nacional, obligatoria, laica y gratuita, $y$, en ese mismo año de 1881, propuso la creación de la Universidad Nacional de México, que no se abrió sino hasta 1910, casi dos meses antes de que estallara la Revolución. En 1884 Sierra fue nombrado director de la Escuela Nacional Preparatoria y durante el último decenio del gobierno de Porfirio Díaz, en 1905, planteó la creación de la Secretaría de Educación Pública y Bellas Artes, de la cual él fue su primer titular. Como tal, reorganizó varias de las carreras que se impartían y crea un sistema de universidades de provincia, entre otras iniciativas. Así, la educación básica la vinculó con los estudios universitarios.

Sierra, junto con otros "positivistas" como Ezequiel A. Chávez, a quien también se le reconoce como coautor de la creación de la Universidad Nacional, fue congruente con sus ideas, pues se expresó contra la "dictadura ilustrada" y propugnó porque el Estado "tenía que progresar por medio de una sistematización científica de la administración pública del pais"."

Don Justo es un modelo de político ilustrado que supo ganarse el aprecio de porfiristas y opositores. De ahí que se comprenda muy bien la simpatía y respeto que le guardaba Díaz y su capacidad para trabajar en un gabinete con el cual disentía en la forma de gobierno. El "Maestro de las Américas" renunció poco antes de noviembre de 1910 y dos años después el propio Francisco I. Madero lo nombró Ministro Plenipotenciario en España, cargo que desempeñó por unos cuantos meses hasta su muerte ocurrida en Madrid el 13 de septiembre de 1912.

A cien años de haber inaugurado Porfirio Díaz la Universidad Nacional, no deja de sorprender la visión de

4 Enciclo: lista de distribución de los usuarios de la Enciclopedia Libre.<enciclo@listas.us.es>

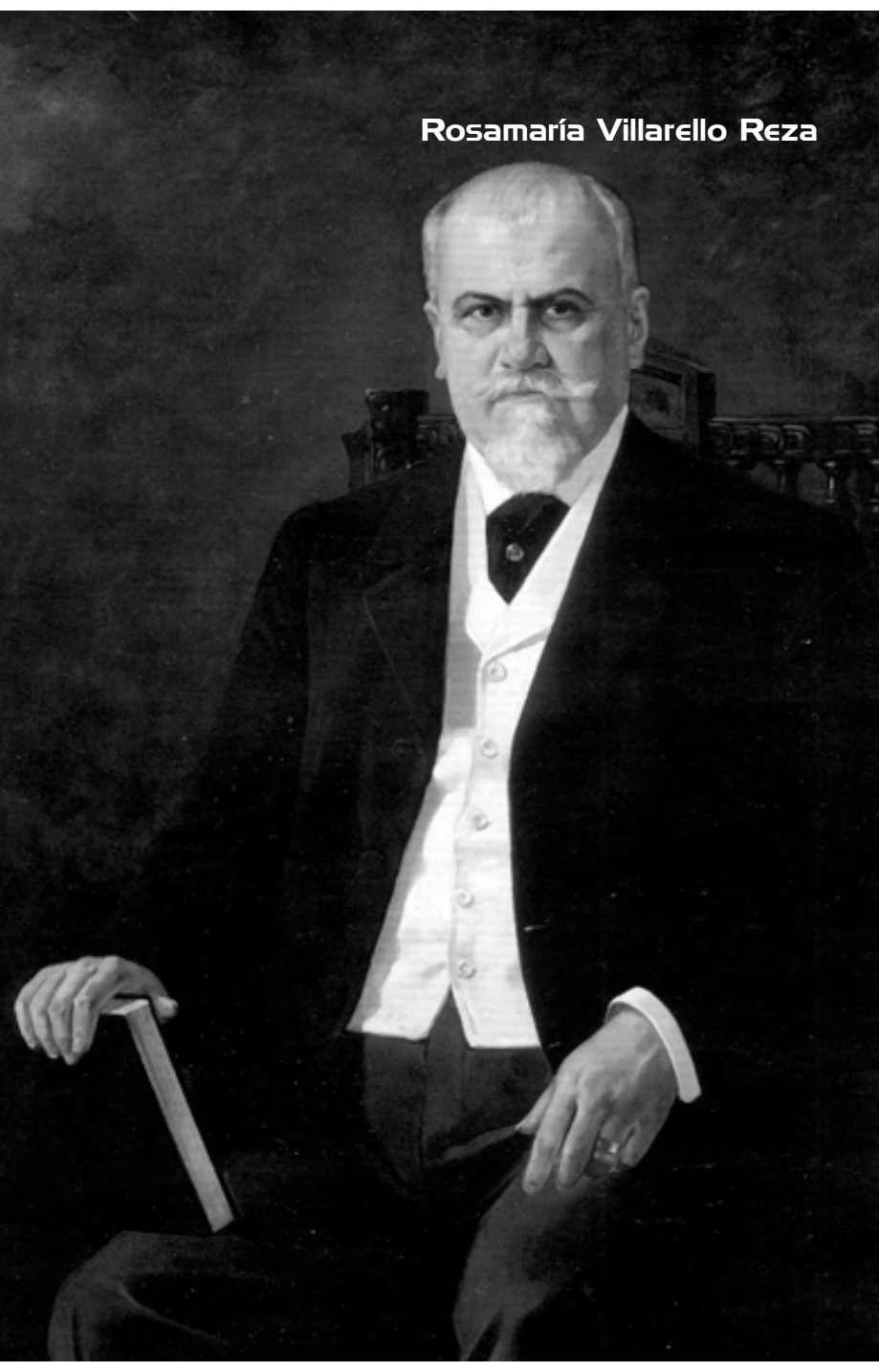

Justo Sierra para ponerse a la altura de muchos países que contaban con instituciones de educación superior. Junto a aquella famosa frase "el pueblo mexicano tiene hambre y sed de justicia", pronunciada en 1893 , hoy más que nunca, a un siglo, no podía ser más certero con otra: "Es la educación la que genera mejores condiciones de justicia, educar evita la necesidad de castigar."

Entre 1900 y 1910 Sierra creó seis bibliotecas públicas más a las 43 existentes, que sumándolas eran $49 .{ }^{5}$ Sin embargo, todavía eran insuficientes ante la creciente demanda educativa en el país aún en plena Revolución y sobre todo porque el estudiantado lo exigía cada vez más, pues ya desde 1868, en que la Escuela Nacional Preparatoria abrió sus primeros cursos, se habían matriculado 900 alumnos, aunque para 1910 los estudiantes universitarios apenas llegaban a mil.

5 Cifra resultante de la suma del número de bibliotecas anteriores. 
A partir de ese año comenzó una nueva era. La apertura de la Universidad representó el clímax del gobierno de Díaz, que con ello festejó a lo grande los cien años de la independencia de México; acto por demás simbólico que daría lugar al más importante proyecto educativo en el siglo $\mathrm{xx} .^{6}$

Desde el primer rector de la Universidad nombrado el día de su creación, el 22 de septiembre de 1910, Joaquín Eguía Lis, también quedaron incorporadas a la institución la Escuela de Altos Estudios (recién creada), la Preparatoria y las escuelas de Medicina, Jurisprudencia y Bellas Artes, las que agruparon parte de sus colecciones bibliográficas respectivas en los edificios en donde se establecieron, así como en la Biblioteca Nacional.

Entre 1913, en que deja la rectoría el licenciado Eguía tras el asesinato de Madero, y junio de 1920 la Universidad tuvo seis rectores. Esta inestabilidad en el cargo es comprensible en la medida que la situación del país no permitía tener una mayor continuidad de la vida académica, así como por las discrepancias al interior de las propias corrientes políticas y filosóficas de la institución tanto de profesores, alumnos y autoridades. Cabe mencionar que algunos de esos rectores, así como otros funcionarios, participaron activamente en la escena política. Durante los rectorados de dos de ellos se incorporó a la Universidad la Escuela Nacional de Odontología y la Biblioteca Nacional, así como la Escuela de Ciencia e Industria Química. ${ }^{7}$

Aún con las revueltas violentas, para 1919 se habían instalado 16 nuevas bibliotecas. ${ }^{8}$ Así se llegó a la cifra de 65 , lo que es atribuible no sólo a la necesidad de contar con un número mayor de centros de consulta pública y escolar y universitaria sino a la voluntad política de los gobernantes de la época, pues la Universidad era parte de la Secretaría de la Instrucción Pública.

6 Hay autores que consideran que fue más un acto político y que la figura de Sierra está sobredimensionada. Garciadiego Dantan, Javier. De Justo Sierra a Vasconcelos: la Universidad Nacional durante la Revolución mexicana. México: El Colegio de México, 1996.

7 Los 100 años de la UNAM. Coordinación Elena Gallegos. México: La Jornada, 2010.

8 Sametz de Walerstein, Linda, op. cit.

\section{José Vasconcelos y la autonomía universitaria}

Uno de los aspectos a destacar del siglo XXI con la retrospectiva que ha dado el centenario de la Revolución mexicana es su reinterpretación. Ello se ha convertido en un ejercicio, sin lugar a dudas importante, para analizar con diferente mirada el proyecto educativo del siglo pasado.

Si hay algo que no se puede negar es el cambio que tuvo México a partir de 1910 en materia educativa, cuando se consolida la idea de ampliar sus beneficios a toda la población y se marca una ruta institucional. Aún con los problemas nacionales comenzó un cambio generacional y la figura de José Vasconcelos tomó una dimensión diferente en 1920, pero igual de importante a la que tuvo Sierra en $1910 .^{9}$

Vasconcelos fue nombrado rector el 4 de junio de 1920. El modelo de Universidad ya no correspondía a las nuevas necesidades de país, sobre todo por el giro "revolucionario" ante un agotado modelo porfirista. Con su experiencia anterior en el gobierno federal su programa incluía: volverla más abierta y popular; abrir un gran programa cultural y desarrollar varias herramientas que consideró indispensables: la creación de un sistema bibliotecario nacional, la extensión de la cultura, la incorporación de determinados sectores de la población (obreros, indígenas y la clase media) a programas de alfabetización; el fomento a la lectura y el acceso fácil a los libros, sobre todo poniendo al alcance de un gran segmento de la sociedad a los grandes pensadores universales.

Esto no hubiese sido posible sin la pasión de Vasconcelos por la lectura, los libros y su gran conocimiento de las bibliotecas más importantes del mundo. Fue un convencido de que habría que voltear a ver las bibliotecas del Norte y tratar de seguir su modelo, no sólo en cuanto a la construcción de espacios apropiados sino a las técnicas bibliográficas, sin descontar los ejemplos que siempre encontró en bibliotecas europeas y en la corriente latinoamericanista. Fue un fuerte impulsor de la participación en congresos de bibliotecarios, pues la veía como una forma de aprender de nuevas corrientes que se expandían por doquier. Pero de Estados Unidos le llegó la

9 GARciadiego DANTAN, Javier, op.cit. 
inspiración en cuanto a la expansión de bibliotecas en todo el país, hasta en las pequeñas poblaciones.

Vasconcelos echó a andar su proyecto bajo la presidencia interina de Adolfo de la Huerta y Álvaro Obregón lo ratifica en el cargo. Si bien el concepto de nacional de la Universidad se había establecido desde la idea de su creación en el siglo pasado y ratificado en 1910, a partir de este personaje cobra otra medida. Durante el año y tres meses que permaneció en la Rectoría llevó a cabo una gran obra. Eran épocas, en definitiva, que había una simbiosis de objetivos culturales y académicos entre los gobiernos y los universitarios, lo que le permitió tener una gran influencia a todo lo largo y ancho de la República.

En su discurso de toma de posesión, Vasconcelos, al referirse al "nuevo sentido del gobierno" dice que cristaliza la Revolución como la última esperanza. "La pobreza y la ignorancia son nuestros peores enemigos; a nosotros nos toca resolver el problema de la ignorancia', y agrega más adelante cuando exige la colaboración de maestros, alumnos e intelectuales: 'en esos momentos yo no vengo a trabajar por la Universidad, sino a pedir a la Universidad que trabaje por el pueblo.'10

Así es que a partir del 20 de junio, a unos días de haber tomado posesión en su administración, inicia sus giras por el país y le encarga a Ezequiel A. Chávez un proyecto en el cual ya habían trabajado en 1915: una ley de federalización de la enseñanza mexicana y la creación de la Secretaría de Educación Pública (SEP), que no se había podido concretar. En el Boletín de la Universidad de noviembre de 1920 se consigna en el artículo 6 de dicho proyecto de ley, que establece la organización de museos escolares y bibliotecas circulantes.

Ezequiel Chávez describió desde 1885 la clasificación decimal usada en Estados Unidos, basado en el método de Melvil Dewey, para la organización de las bibliotecas y el trabajo que hacian los bibliotecarios como agrupación de trabajadores para la "civilización del pueblo".11

10 Datos de Linda Sametz de Walerstein.

11 ldem.
Durante su gran campaña de alfabetización, Vasconcelos puso en marcha la fundación de bibliotecas para complementar la educación, "pues no era suficiente enseñar a leer, sino proporcionar libros... para que adquiera la gente conocimientos útiles". De ahí que creó el Departamento de Bibliotecas Populares desde su arribo a Rectoría, nombrando a Julio Torri su director. Aunque la idea no era original, pues existía desde el siglo xvI, las nuevas bibliotecas le proporcionaban al pueblo "lecturas amenas e instructivas".

Con todo, se llegó a contar para entonces con cerca de 72 bibliotecas en la capital, pero éstas eran deficientes y cada una contaba con 100 volúmenes. Según Vasconcelos, tampoco se podría afirmar que eran modernas, "porque no tenían personal calificado y entrenado para atender al público y adquirir, clasificar, catalogar y conservar los libros... Inclusive la Nacional, aunque se encontraba en un bello edificio pero impropio, ha sido y sigue siendo almacén de libros de información y lectura." ${ }^{2}$

Vasconcelos también fue un gran promotor de traducciones al español de los principales autores que se leían en el mundo y se lanzó a crear la Casa Editorial. Grandes hombres dedicados a la cultura estuvieron al frente de bibliotecas y ediciones e inclusive Álvaro Obregón aceptó que los Talleres Gráficos de la Nación formaran parte de la Universidad Nacional.

Dos meses después de su arribo a la rectoría, Vasconcelos inauguraba salas de lectura en varios estados de la República, lo que aprovechaba para recibir adhesiones a su propuesta de creación de la Secretaría de Educación Pública (SEP). En seis meses repartió 1905 libros entre bibliotecas públicas y otros destinatarios como escuelas, oficinas, corporaciones obreras y estudiantiles.

El Boletín de la Universidad de diciembre de 1921, mencionado por Sametz, publicó que "el Presidente Obregón informaba que se habían repartido 20 mil volúmenes y estaban por hacerlo con más de 30 mil en la medida que los ayuntamientos respondan a la acción federal". La cifra que da esta autora es de 47627.

12 Idem. 


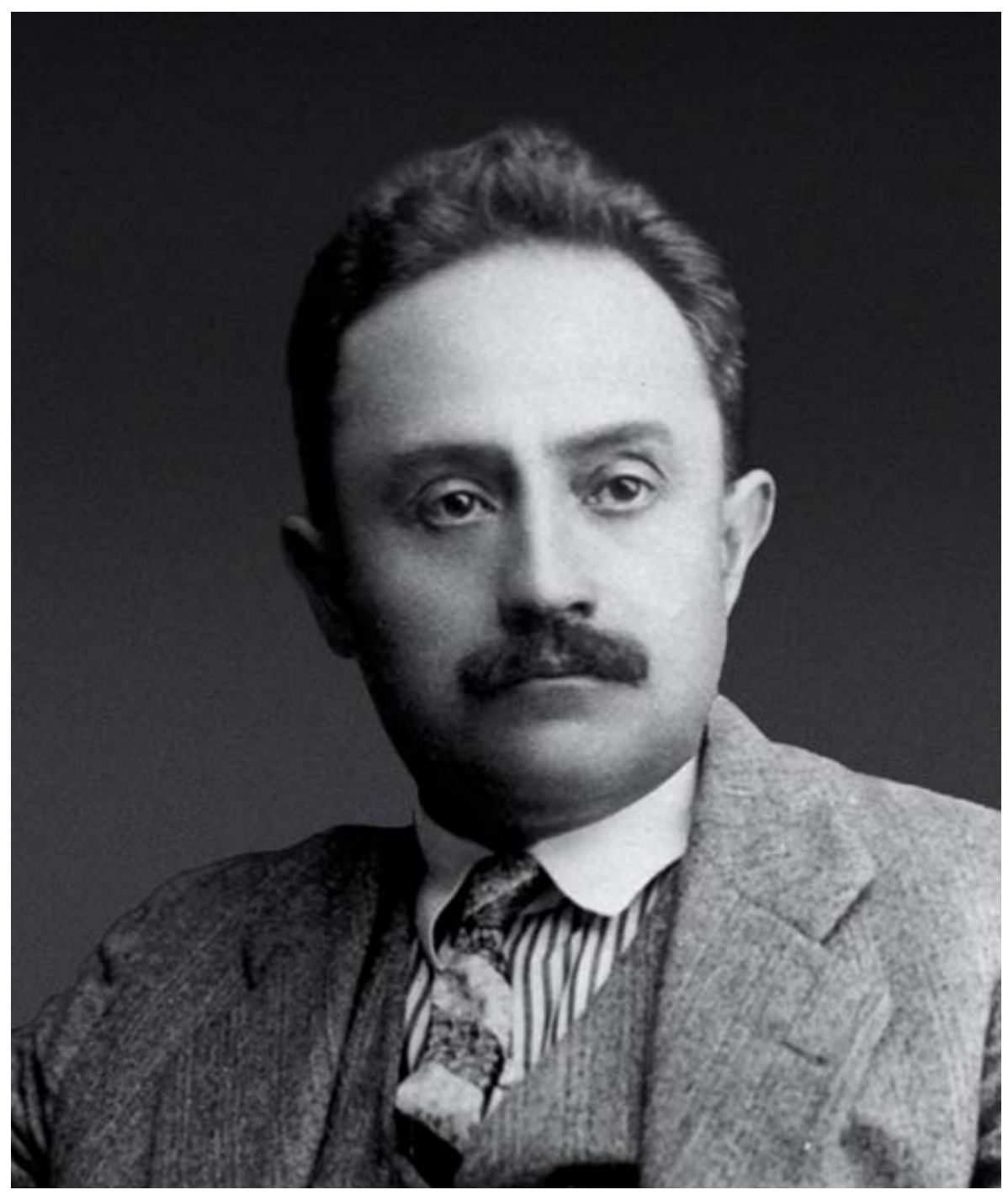

Vale la pena destacar otros aspectos en apoyo a los servicios bibliotecarios de la Universidad: abrió un turno dominical y proveyó de puestos a personal que cumpliera los requisitos de conocimiento de lenguas y biblioteconomía (que supieran guardarlos, ordenarlos, registrarlos y manejarlos adecuadamente); y a los dependientes de libros, así como a los encargados, oficiales catalogadores, oficiales clasificadores y ayudantes, se les aplicaban exámenes de ortografía.

La SEP inició sus labores en septiembre de 1921, unos meses después de que Obregón asumiera la presidencia. A partir de su gobierno, en un período de mayor estabilidad, José Vasconcelos asumió la titularidad de dicha dependencia el 12 de octubre del mismo año y continuó la obra que había iniciado siendo rector.

Dentro de la organización de la Secretaría creó varios departamentos, entre los que se cuenta el de Bibliotecas y Archivo, que tuvo la función de establecer un sistema nacional más propenso al modelo norteamericano. Profundizó en su idea de proveer más libros en castellano e introducir el préstamo a domicilio, y en la obtención de fondos para sostenerlas y medidas reglamentarias para el funcionamiento del Archivo General de la Nación y la administración de la Biblioteca Nacional. El Departamento de Bibliotecas de la

En cuanto a las bibliotecas fundadas entre agosto de 1920 y noviembre de 1921, la misma autora, basándose en dicho Boletín de este último mes, menciona la fundación de 176 bibliotecas en diferentes entidades de la República, promediando casi 13 mensuales, pero de ellas 165 las estableció en 1921. También indica en otro apartado de su libro que Vasconcelos había creado 198 en total y que continuó desarrollando, así mismo, las bibliotecas universitarias de aquellas escuelas ya incorporadas que pertenecían a la institución: la de Bellas Artes, Música y del Museo Nacional de Arqueología, Historia y Etnología.

\begin{abstract}
Universidad pasó a la SEP y se hizo un nuevo reglamento.
\end{abstract}
Aunque desde tiempo atrás ya se recibian y catalogaban revistas y periódicos, para 1923 se contaba con un número muy importante de ellos, provenientes de Europa, Hispanoamérica y de los estados de la República. En 1924 había un número impresionante de suscripciones y se comenzó su catalogación, según el sistema de la biblioteca de la Secretaría. Así también, la ya fundada Dirección Central de Bibliografía tuvo la función de hacer los inventarios y clasificar todo lo que se publicara en el país y llevar a cabo en este último año la primera Exposición del Libro Mexicano. 
Según el recuento del propio Vasconcelos, desde su paso por la Universidad se habían fundado $1923 \mathrm{bi}$ bliotecas y repartido 182015 volúmenes, un buen número en el extranjero, tanto en embajadas como en consulados. El mayor reparto tuvo lugar en 1922. La división que hace de ellas es la siguiente: bibliotecas públicas, obreras, escolares, diversas, ambulantes rurales y circulantes. Las fundadas por la Universidad Nacional ascendieron al número de 141 , pero si se toma en cuenta que la Universidad dependía del gobierno y Vasconcelos siempre recurrió a ella para continuar con sus propósitos, entonces veremos que la participación de la institución fue mucho más allá de esa cifra. ${ }^{13}$

Se considera que una de las obras más significativas de Vasconcelos fue la creación de la Biblioteca Iberoamericana o Hispanoamericana. A su inauguración asistieron, el 6 de enero de 1924, desde el presidente Obregón y todo su gabinete hasta los representantes de varias naciones de Latinoamérica y Europa. Desde hacía varios años atrás, Vasconcelos la había concebido para dar a conocer las grandes riquezas de la región a través de sus libros, principalmente en español, sin dejar fuera los de otras lenguas. La colección llegaba a 10 mil publicaciones y era una forma, según la veía, de ilustrar al pueblo mexicano con información de primera mano. No descuidó el hecho de preparar a bibliotecarios con nuevas técnicas por lo que tuvo la previsión de enviarlos a Estados Unidos para que se especializaran en el sistema norteamericano; así se introdujo el "sistema de tarjeta" para la localización rápida de las obras.

El lema de la Universidad "Por mi raza hablará el espíritu" es de su acuñación, pues Vasconcelos era un fiel creyente de la raza cósmica, la iberoamericana. En 1924 renuncia a la SEP por estar en desacuerdo con el candidato presidencial, posición a la que aspiró posteriormente. ${ }^{14}$

\footnotetext{
13 Idem.

14 Después de un largo periodo de exilio y cárcel se dedicó a escribir y en 1940 es nombrado director de la Biblioteca Nacional, cargo que mantuvo durante 10 años, pero ya sin el brillo anterior. Otro de los servicios importantes que prestó, fue el traslado de la Hemeroteca Nacional de los antiguos templos donde se encontraba. Murió en 1959.
}

Con la sucesión de los siguientes rectores se comienzan a expandir las escuelas, facultades, institutos, centros, para atender más áreas del conocimiento, así como oficinas administrativas y por consiguiente las bibliotecas. Son más de 25 las que se abren con el crecimiento de carreras que van a requerir nuevos títulos y más volúmenes de toda clase de documentos científicos, humanísticos y económico-administrativos necesarios para la enseñanza y la investigación.

En 1924 asume la jefatura del Departamento Técnico de Bibliotecas Don Tobías Chávez, quien por cierto fue uno de los primeros en presentar examen de bibliógrafo en 1923. Él se va a ocupar del Departamento de Bibliotecas y de lo que ya se concebía como Biblioteca Central, en una instalación del centro de la ciudad y continuar la labor de la "Biblioteca Universitaria". ${ }^{15}$

El tema de la autonomía, de vieja data, comenzó a tomar forma y se promulgó a través de la Ley Orgánica de 1929, por lo que el primer rector electo por el Consejo Universitario, a propuesta de una terna enviada por el presidente Emilio Portes Gil, fue Ignacio García Téllez, quien permaneció hasta 1932. A su antecesor, Antonio Castro Leal, se le debe el reconocimiento de la autonomía. La institución se convierte así en Universidad Nacional Autónoma de México, unam.

Manuel Gómez Morín lanzó la nueva Ley Orgánica y la elaboración del primer Estatuto de la Universidad; Luis Chico Goerne y Gustavo Baz Prada expidieron el segundo y tercer estatutos.

Es hasta la gestión de Rodolfo Brito Foucher que se expide la Ley sobre la Fundación y Construcción de Ciudad Universitaria (cu). Con la de Alfonso Caso se da la instalación del Consejo Constituyente Universitario, aprobando una nueva Ley Orgánica en 1945, que sigue vigente hasta ahora, en 2011. Por primera vez, en ese entonces, la recientemente formada Junta de Gobierno nombró a un rector: Genaro Fernández Mac Gregor, y, ya siendo rector el médico Salvador Zubirán recibe los terrenos para edificar la Ciudad Universitaria

15 De ahí proviene el nombre de la Revista que hoy tenemos en las manos. 


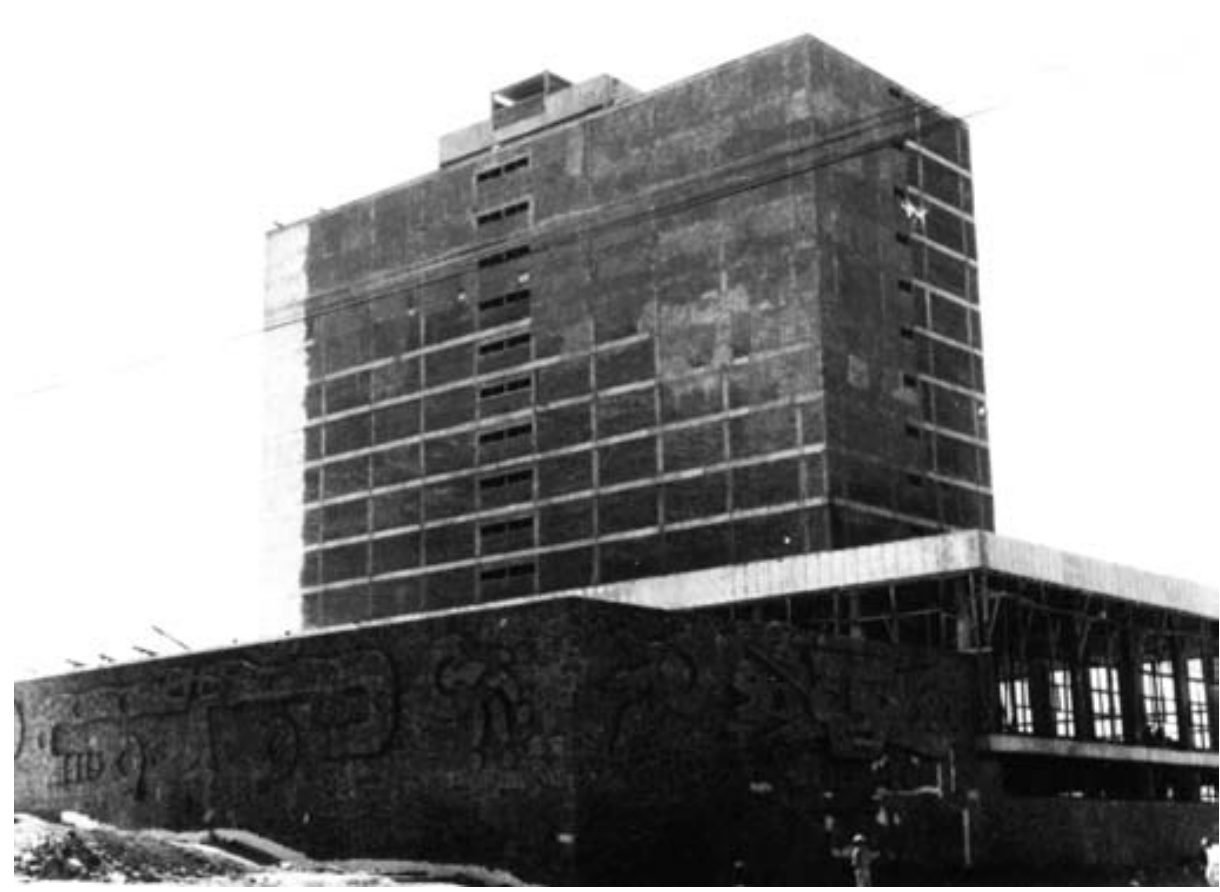

de manos del presidente Manuel Ávila Camacho el 4 de marzo de 1946. A Luis Garrido Díaz, primer rector que termina su período y es reelecto, le concierne organizar en 1951 la celebración por los 400 años de la fundación de la Real Universidad de México. Garrido permaneció hasta ver terminada la primera etapa de la construcción de Ciudad Universitaria. ${ }^{16}$

\section{La Ciudad Universitaria y la formación del Sistema Bibliotecario}

Al rector Nabor Carrillo Flores le tocó el traslado de la UNAM del centro de la ciudad de México a los edificios de Ciudad Universitaria (cu). El 22 de marzo de 1954, el presidente Adolfo Ruiz Cortines entregó oficialmente las instalaciones e inauguró los primeros cursos en los edificios del Pedregal de San Ángel.

Como es natural, esta fue una etapa de grandes esfuerzos y de gran actividad, por lo que representaba trasladar equipos, mobiliario y acervos bibliotecarios;

16 Datos consultados de diferentes fuentes, inclusive universitarias, que no siempre coinciden las fechas precisas. así mismo, la adaptación de los profesores, investigadores, administrativos y estudiantes a la nueva sede.

El Departamento de Bibliotecas y el de la Biblioteca Central se instalaron en la Torre de Rectoría y eran dos organismos diferentes hasta su ubicación en el edificio que hoy alberga los Murales de Juan O' Gorman. El edificio de la Biblioteca Central (BC), destinado originalmente para la Biblioteca Nacional y la Hemeroteca Nacional, abrió sus puertas el 5 de abril de 1956. ${ }^{17}$ A partir de entonces, la $B C$ se va a convertir en el eje de la vida universitaria y en el emblema de nuestra Casa de Estudios, por su belleza arquitectónica, sus murales y sobre todo, por su importante colección de documentos bibliográficos.

Ya instalados en Ciudad Universitaria, y al ir dejando el barrio universitario en el centro de la capital, las siguientes autoridades tuvieron que enfrentar otra serie de problemas, conflictos inherentes a una nueva época, pero a la vez con muchas satisfacciones de lo que iba logrando la UNAM. La cifra de bibliotecas propiamente universitarias era de 38: "contaban con 2 mil volúmenes, 556 publicaciones periódicas nacionales y extranjeras, libros de reserva, libros de texto y obras básicas

\footnotetext{
17 La Biblioteca Nacional y la Hemeroteca estaban en custodia de la UNAM desde1929 y tienen una historia aparte, aunque, como se señala en el artículo, han tenido una formación casi paralela con la UnAM desde sus orígenes. Aunque inicialmente se llevaron a cabo traslados de materiales documentales al edificio del Pedregal, fueron devueltos una buena parte de ellos en años posteriores, ante la falta de consenso de trasladarlas a CU, lo que después ocurrió en 1979. Los 100 años de la UNAM. Coordinación Elena Gallegos. México: La Jornada, 2010.
} 
y la Sección de Material Audiovisual para un futuro". ${ }^{18}$ Los mismos autores mencionan que el Archivo General de la UNAM de 1957 consigna que a la sazón había 40 bibliotecas, incluyendo a la Nacional, y que la Central poseía 32 mil volúmenes; pero para 1960, la cifra sube a 40 mil. Esta última asumió las funciones generales para todas las bibliotecas: las notas bibliográficas, la catalogación, las adquisiciones y su registro y más tarde las secciones de tesis, canje, donaciones, fotocopia y microfilm, así como la de exposiciones.

Don Tobías Chávez permaneció en el cargo de jefe del Departamento Técnico de Bibliotecas hasta 1965, cargo que ejerció por 30 años. Sin lugar a dudas, a este bibliotecario se le debe el establecimiento de bases más sólidas y de un conjunto de criterios técnicos. Entre las funciones que desempeñaba dicho Departamento estaba el acrecentamiento, inventario y revisión de las obras y su distribución; la donación; la elaboración de estadísticas de libros y lectores; la distribución del material para el trabajo de las bibliotecas y su cuidado y la administración de la BC, entre otras.

Vale destacar que en 1926 se aprobó el primer Reglamento para las Bibliotecas Universitarias; en diecisiete artículos se enumera el procedimiento del funcionamiento de uso y préstamo de libros y del comportamiento de los usuarios. En junio de 1933 el Consejo Universitario lo derogó y promulgó el Reglamento de la Dirección General de Bibliotecas de la Universidad Nacional de México (sic) como oficina coordinadora del trabajo técnico. Es el primer ordenamiento regulador a través de una dependencia administrativa acorde con el continuo desarrollo bibliotecario. Contó con 67 artículos que reglamentaban los servicios de la "Biblioteca de la Universidad Nacional", el desarrollo del personal, sus integrantes y funcionarios, así como de sus atribuciones.

18 Rojas, Juan Romeo, Hernández Sánchez, Gloria Adriana, ZetTER LEAL, Julio. Destino y vocación: biblioteca universitaria. En: Universidad Nacional Autónoma de México. Dirección General de Bibliotecas. Biblioteca Central: libros, muros y murales, 50 Aniversario..., 2006.

\section{La Dirección General de Bibliotecas, eje del Sistema Bibliotecario Universitario}

La DGB comenzó a operar en 1965 con un ordenamiento coherente. Su primer director general, el doctor Armando M. Sandoval, quien sólo estuvo en su encargo unos meses, continuó construyendo los cimientos que había puesto su predecesor, fundamentales para mantener una línea ascendente para que las bibliotecas universitarias comenzaran a funcionar como un sistema.

Pero es hasta 1990 cuando se establece el "Sistema Bibliotecario Universitario" como tal, que le da cuerpo el Reglamento General del Sistema Bibliotecario de la Universidad Nacional Autónoma de México (sıBUnAM). A éste me referiré más adelante.

A partir de la gestión de Sandoval, el desarrollo en cierne del Sistema Bibliotecario de la UNAM abarcó las necesidades del constante número de bibliotecas que se iban creando y sobre todo la atención de todos aquellos problemas técnicos que iban surgiendo. Esta medida de nombrar a un científico de larga experiencia, por parte del rector Ignacio Chávez, reflejó el interés de darle una significación diferente a las bibliotecas en el contexto de la educación superior.

La maestra Margarita Almada señala en su testimonio por los 50 años de la Biblioteca Central, que tales eran los conocimientos de Sandoval que más adelante el rector Pablo González Casanova, en 1971, lo nombra director del Centro de Información Científica y Humanística, que tuvo un "destacadísimo papel en la innovación y desarrollo de servicios de información utilizando por primera vez en la Universidad y en el país las nuevas tecnologías de la información". ${ }^{19}$ A él se le debe la existencia de bases de datos ampliamente consultadas hasta nuestros días: CLASE, PERIÓDICA y Bibliografía Latinoamericana, en una época en que habian hecho irrupción mundial las tecnologías para las consultas.

El siguiente rector, el ingeniero Javier Barros Sierra, nombró como directora General de Bibliotecas a Alicia Perales Ojeda, quien asume sus funciones desde 1966

19 Ibid., p. 187-188. 




hasta 1973. Le tocaron años duros para la UNAM bajo tres rectores: Barros, Pablo González Casanova y Guillermo Soberón Acevedo. La labor de Perales al frente de la DGB consistió principalmente en ampliar y organizar los servicios, cambios de estantería y una reorganización del uso de los pisos de la BC, pues además se encontraban en el mismo edificio otras oficinas de la UNAM.

Con el doctor González Casanova y la ampliación del subsistema del bachillerato a través de la instalación de cinco planteles del Colegio de Ciencias y Humanidades ( $\mathrm{CCH}$ ), más los nueve de la Escuela Nacional Preparatoria, su población estudiantil requirió, así mismo, de acervos bibliotecarios acordes al nivel de la enseñanza media superior. Por consiguiente, se tuvieron que construir las bibliotecas en cada plantel.

Al igual, la creación del Sistema de Universidad Abierta, ante la imposibilidad de la UNAM de continuar recibiendo a estudiantes en la modalidad presencial, contribuyó a elevar el número de títulos y volúmenes que cada año se han ido requiriendo para la consulta de alumnos y profesores.
Al arribo en enero de 1973 del doctor Guillermo Soberón, se creó la Escuela Nacional de Estudios Profesionales (ENEPS) con varios campi, convertidos años después en FES (facultades) y distribuidos en diferentes delegaciones del D.F. y en el Estado de México; mas varios centros, institutos facultades y escuelas y el Centro Cultural Universitario, lo que aumentó nuevamente la cifra de bibliotecas. En la primera gestión de Soberón, quien concluyó dos períodos en un clima de tranquilidad y estabilidad de la UNAM, se nombró al historiador Adolfo Rodríguez Gallardo para dirigir la DGB, quien permaneció hasta 1977 en una primera ocasión. Para este último año se habían adquirido 113 mil 558 volúmenes para todo el Sistema y 6 mil 858 para la $\mathrm{BC}^{20}$ Fueron años en que se presentó una realidad ineludible, pues con el crecimiento poblacional universitario comenzaron a aumentar las compras tanto de libros como de revistas, lo que hizo pensar en ampliar los espacios para guardar esos materiales.

En el testimonio que presenta el propio Rodríguez Gallardo con motivo de los 50 años de la Biblioteca Central, se aboca principalmente a dar cuenta del im-

20 Ibid. p. 188 
portante avance que hubo en el Sistema Bibliotecario gracias a la profesionalización del personal, pues los pocos bibliotecarios que había con estudios en un inicio apenas llegaban a 10. Lo que benefició su idea de tener profesionales fue la revisión del Estatuto del Personal Académico que facilitó la inclusión de personal académico en las tareas de la DGB. A la vez, se reconoció que la dependencia podía contar con técnicos académicos. Rodríguez narra que a ello se debió principalmente la creación del Centro Universitario de Investigaciones Bibliotecológicas, CUIB. ${ }^{21}$

21 El trabajo bibliotecario data del siglo xvı en la Nueva España y fue evolucionando conforme al desarrollo editorial. Se inició con autodidactas, muchos de ellos con una gran cultura, los que posteriormente se aplicaron en desplegar su ingenio para ordenar los libros. Los estudios de la bibliografía hispano-mexicana para el comienzo del siglo xx trajeron consigo que ilustres personajes clasificaran los conocimientos humanos y los organizaran. Entre 1915 y 1917 surgió la Escuela Especial para Bibliotecarios, Archiveros y Bibliógrafos. La SEP inició lo que para 1944 va a ser la Escuela de Biblioteconomía y Archivonomía (ENBA) debido a la necesidad de contar con mayor personal especializado con el crecimiento de las bibliotecas y sus colecciones. Tenía 54 alumnos. El 9 de abril de 1956 inició sus cursos el Colegio de Biblioteconomía y Archivonomía de la UNAM en la planta alta de la Biblioteca Central. El proyecto fue activado por el secretario general, Dr. Efrén C del Pozo, al año siguiente y tenía como objetivo "establecer una escuela de graduados para la preparación de profesionales, con objeto de levantar el nivel de la biblioteconomía en México, así como para proveer a la universidad y a las demás bibliotecas de México del personal adecuado".

Cuando ya las bibliotecas de las dependencias universitarias tenían grados variables de organización, se creó la maestría en Bibliotecología en 1972. Fue el primer posgrado de esta disciplina que se establece en México y para 1998 se comienza a ofrecer los programas de maestría y doctorado en Bibliotecología y Estudios de la Información con el respaldo de la Facultad de Filosofía y Letras y el CuIB, para "formar cuadros de alto nivel académico que hagan frente a los retos disciplinares y a la organización y administración de bibliotecas en un ambiente diverso". El CUIB tiene su origen en la DGB y por acuerdo del rector Octavio Rivero Serrano se adscribe a la Coordinación de Humanidades en 1981; ha sido uno de los pilares modernos de la disciplina. Como misión destaca: "llevar a cabo investigaciones teóricas y aplicadas sobre los fenómenos relacionados con el
La maestra Margarita Almada Navarro, química de profesión, sustituyó al maestro Rodríguez Gallardo en junio de 1977. Ella prosiguió la tarea de abatir el enorme rezago de los procesos técnicos y fortalecer la introducción de los servicios computacionales para los mismos. Publicó la Guía para el uso del catálogo y los servicios que proporciona la biblioteca; se inicia la capacitación de usuarios por medio de guías de instrucción; se intensificaron las adquisiciones nacionales y las internacionales se adquirían con agencias distribuidoras dándole mayor transparencia a las compras, que ya para entonces habían logrado elevarse sustancialmente. Almada no es la excepción en hacer mención de los logros de la Biblioteca Central e informa que para el año de 1979 había un promedio de lectores de 1709 al día y el préstamo de libros ya alcanzaba la cifra mensual de $41233 .{ }^{22}$ También a la maestra le correspondió iniciar los trabajos de remodelación de la $\mathrm{BC}$ en 1980 y adecuar las instalaciones bibliotecarias.

A la llegada del rector Octavio Rivero Serrano es nombrado director General de Bibliotecas el politólogo y administrador Rodolfo Jiménez Guzmán, a partir de enero de 1981. Prosigue con la remodelación de la Biblioteca Central que permanecía cerrada desde el año anterior y se replanteó la necesidad de establecer las estanterías abiertas, o sea que cada usuario pudiera acceder sin barreras de por medio a los anaqueles, como en las grandes bibliotecas modernas. La BC se

libro y la información registrada en impresos y otros medios, siendo algunos de ellos: sus formas de generación, su selección y adquisición, su organización y representación, así como los medios, procesos y tecnologías utilizados para su almacenamiento, recuperación y distribución a diversos sectores de la sociedad". Su primer director fue el doctor Adolfo Rodríguez Gallardo, nombrado en 1982, y titular de la Dirección General de Bibliotecas, cargo que actualmente ocupa. (Fuentes: Cincuenta años de estudios universitarios en bibliotecología: una revisión de su historia. Judith Licea de Arenas, coordinadora...,2007.; Universidad Nacional Autónoma de México. Centro Universitario de Investigaciones Bibliotecológicas [en línea]. <http://cuib.laborales.unam.mx/>; Universidad Nacional Autónoma de México. Dirección General de Bibliotecas [en línea]. <http://dgb.unam.mx/>).

22 Los 100 años de la UNAM..., op. cit. 
reabrió en 1983 y se llevaron a cabo las reuniones de evaluación bibliotecaria. Así mismo, se logró la microfilmación de 12 mil tesis. Entre otras cuestiones, Jiménez tuvo que enfrentar el enorme rezago de procesos técnicos que no se concluía. Ya para entonces la BC recibía un promedio de 6 mil lectores diariamente, según él menciona en su propio testimonio publicado en el libro de los 50 años de la Biblioteca Central.

Desde los años anteriores la construcción de nuevos edificios para bibliotecas comenzó a tener un interés particular, en el sentido de que anteriormente las mismas se situaban en lugares poco adecuados o improvisados. Inclusive, se consideró la instalación de bibliotecas conjuntas para los institutos de investigación en espacios comunes y las bibliotecas de centros, escuelas y facultades también se fueron modificando, lo que dio paso a que su construcción tomara otro cariz en el sentido de concebirlas conforme a normas establecidas para la conservación de las colecciones y los equipos técnicos y electrónicos.

Al inicio del rectorado del doctor Jorge Carpizo, 19851988, es nombrado nuevamente el doctor Adolfo Rodríguez Gallardo para un segundo período al frente de la DGB. A él le correspondió cerrar en el año 2000 un ciclo de 90 años de desarrollo permanente de las bibliotecas universitarias y acompañar la evolución de la UNAM junto con otros rectores que sucedieron a Carpizo: José Sarukhán Kérmez (1989-1996) y Francisco Barnés de Castro (enero 1997-noviembre 1999).

Durante este largo período se renovó el trabajo de planeación y se asesoró la construcción y diseño de 20 bibliotecas, como se señala en los dos volúmenes de los libros Nuevos edificios para las bibliotecas universitarias. Desarrolló un Programa de Orientación de Usuarios y un Programa de Publicaciones; de hecho el primer volumen, publicado en 1996, de los nuevos edificios fue elaborado bajo este Programa. En julio de 1990 se aprobó el Reglamento General del Sistema Bibliotecario de la unam (que sustituye al de 1933) lo que a partir de entonces se comenzó a denominar oficialmente así, como sistema (sBu). En su artículo $6^{\circ}$ a la letra dice: El Sistema Bibliotecario Universitario es el conjunto funcional constituido por las unidades que proporcionan servicios bibliotecarios en las diferentes dependencias de la UNAM y por los organismos que coordinan y apoyan la gestión de dichas unidades.

En tal reglamento se manifiesta que "la Dirección General de Bibliotecas es el núcleo del SBu y que sus relaciones se establecen tanto de manera horizontal como vertical entre las diferentes partes del Sistema cuyos objetivos resumidos son: el establecimiento de criterios académicos de planificación y prestación de los servicios; proporcionar esos servicios de manera eficiente y adecuarlos a los avances de la ciencia y la tecnología. Para ello el SBU instituyó sus órganos reguladores: un Consejo, un Comité Asesor, la propia DGB, las bibliotecas universitarias y las Comisiones de Bibliotecas.

Para entonces desaparecieron algunas bibliotecas, se fusionaron otras y se abrieron más. Con Sarukhán se hizo el primer enlace satelital de la Red Universitaria de telecomunicaciones a la actual Internet, clave en el desarrollo de las nuevas tecnologías aplicadas también a las bibliotecas. Con Barnés se constituyeron los campi que se desconcentraron en Juriquilla, Querétaro, y en Morelia, Michoacán. Nuevamente hubo que conformar sus respectivas bibliotecas. ${ }^{23}$

En este período se abrieron cursos de educación continua y actualización para el personal, se asesoró a muchas bibliotecas y la DGB se fue transformando en la capacitadora de personal bibliotecario en el país. Se continuaron impulsando las bases de datos que siguen en permanente consulta: LIBRUNAM, SERIUNAM, TESIUNAM Y EUTERPE. Se creó también MAPAMEX.

En 1995 hubo que cambiar los equipos de cómputo y se adquirió un nuevo sistema administrador de bibliotecas, que resultó ser el ALEPH, que se fue instalando en casi todas las bibliotecas universitarias.

Cabe señalar que de una u otra forma esta estructura del Sistema ha permitido la buena marcha de las bibliotecas que, sin embargo, en algunas de sus partes, no han funcionado estrictamente como lo marca el regla-

${ }^{23}$ Los 100 años de la UNAM..., op. cit. 
mento vigente, razón por la que en los siguientes años se ha venido considerando su revisión, más acorde a los nuevos tiempos; sobre todo pensando en que cada día se producen un mayor número de documentos y diferentes repositorios de los mismos ante la irrupción de las nuevas tecnologías digitales.

Sólo en 20 años, de 1976 a 1996, la colección bibliográfica universitaria pasó de 650 mil volúmenes a cerca de 9 millones de piezas documentales, ${ }^{24}$ y eran 16 millones aproximadamente por año los usuarios, por lo que se han ido incrementando las asignaciones presupuestarias, con una importante participación de recursos provenientes de otras fuentes financieras.

Fueron años también en que el número de bibliotecas varió ante la construcción de los nuevos edificios por el incremento de los acervos, estanterías y nuevos horarios de atención a usuarios, así como la automatización de los servicios, a tal grado que de 200 pasan a 164 y posteriormente en 1996 se contaba con 143 , divididas por subsistemas.

Dentro del Programa de Desarrollo Institucional lanzado por el rector Barnés de Castro se tomó la decisión de incorporar el Centro de Información Científica y Humanística a la DGB con el rango de subdirección de Servicios Especializados, en congruencia con el dar un mayor impulso a la aplicación de las nuevas tecnologías de la información en las bibliotecas, lo que a la distancia se ve como un gran acierto, pues de esta forma el Sistema Bibliotecario se ha visto reforzado.

El testimonio del doctor Rodríguez Gallardo concluye con las siguientes palabras: Todos los logros convirtieron al Sistema Bibliotecario de la UNAM en el paradigma de las bibliotecas universitarias mexicanas. ${ }^{25}$

Al inicio del nuevo siglo y después de una larga suspensión de labores en 1999, tomó posesión como rector en noviembre de 2000 el Dr. Juan Ramón de la

24 Nuevos edificios para las bibliotecas universitarias. Coordinador general Adolfo Rodríguez Gallardo, p. 24 -25.

25 Rodríguez Gallardo, Adolfo. El personal bibliotecario académico de la Universidad, p. 235.
Fuente. Le correspondió realmente regresar a la vida a la UNAM, pues inclusive se hablaba de que sería cerrada por el Gobierno Federal. Después del hartazgo generalizado de la comunidad universitaria por la falta de una vida académica normal, la tarea del rector consistió prácticamente en la reestructuración de la convivencia y del tejido social de la comunidad universitaria. Muchas fueron las acciones que tuvo que llevar a cabo: la principal, elevar nuevamente la calidad académica de la Universidad, cuyo prestigio estaba en entredicho, y colocarla dentro de las 100 mejores instituciones de educación superior del mundo.

Con el reforzamiento de los programas de educación a distancia y educación abierta a través de la Coordinación de Universidad Abierta y Educación a Distancia, que funciona desde la década de los noventa, los beneficiados han llegado a la cifra de más de $\mathbf{3 0 0}$ mil personas anuales en promedio. Ello ha requerido más recursos electrónicos para consulta de los demandantes.

Otros aspectos no menos importantes de la rectoría de de la Fuente fue haber logrado que la UNESCO reconociera al campus de Ciudad Universitaria como Patrimonio de la Humanidad y uno de los factores más importantes para tal decisión fue la gran obra arquitectónica de la Biblioteca Central. Además, se iniciaron las transmisiones con señal propia de TV UNAM, se inscribió con letras de oro el nombre de la UNAM en la Cámara de Diputados y se celebraron los festejos por los 450 años de la Real y Pontificia Universidad de México.

El rector de la Fuente incluyó en su equipo de trabajo a la maestra en historia Silvia González Marín, quien se hace cargo de la Dirección General de Bibliotecas.

De inicio, el objetivo que se fijó González Marín fue devolverle a la Biblioteca Central su carácter de biblioteca modelo rescatando la idea original en el uso de sus espacios, ampliando su horario de trabajo, creando nuevos espacios y modernizando los existentes, academizando sus funciones y desarrollando actividades culturales ${ }^{26}$ Así es que desde entonces se

26 Palabras de Silvia González Marín, con motivo de los 45 años de la BC, 2001 
lanzó a la tarea de remodelarla, actividad en la que ocupó gran parte de los dos periodos que cubrió como directora. Veía a la BC como el rostro de cu y en general de la UNAM, por lo que de ahí se entienda su embeleso por sus murales y su objetivo de convertirla en un verdadero lugar de recreación y cultura.

En esos años se lanzó a la tarea de solicitar mayores fondos para la obra que emprendería e inclusive se lleva a cabo una campaña financiera en pro de la remodelación y equipamiento de la BC. Con el lema de la Biblioteca Central se ilumina para ti, que daba un nuevo esplendor nocturno a los murales

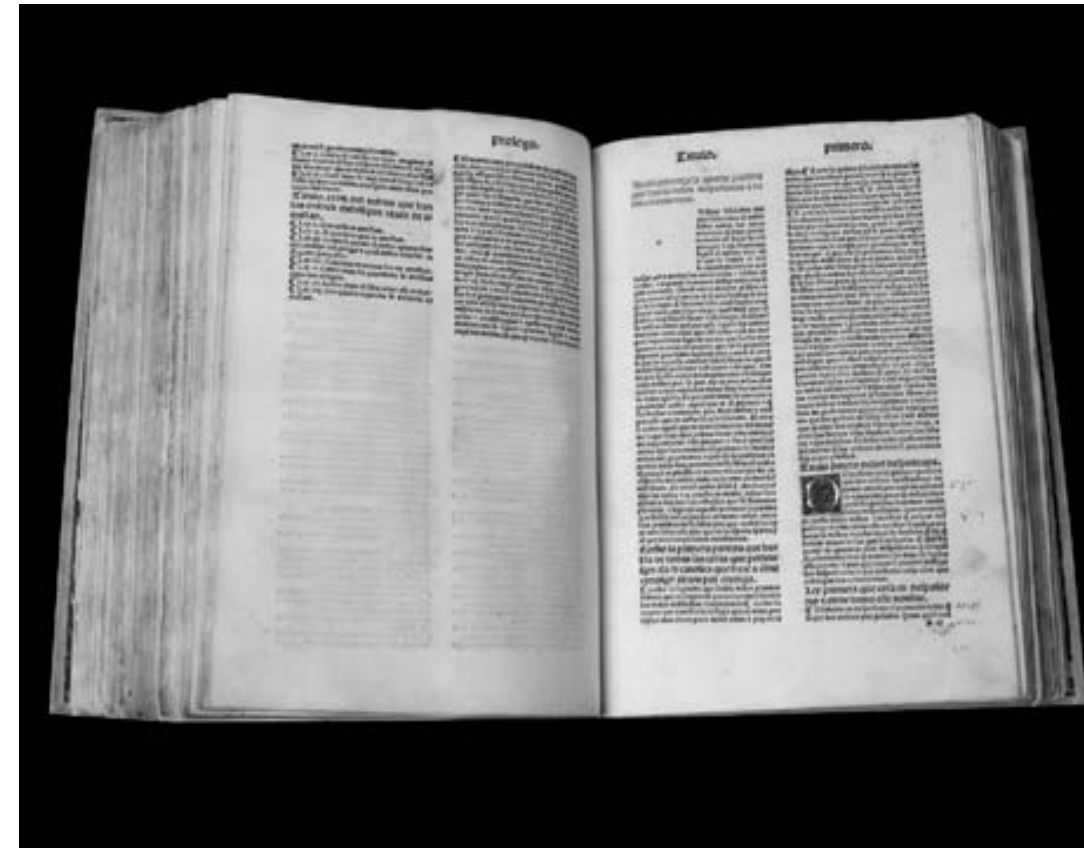

González Marín estableció conforme a las nuevas necesidades bibliotecarias los comités del Libro Electrónico, de Evaluación de Recursos de Información Electrónica, el Interno de Cómputo, así como uno Editorial. Por primera vez la $\mathrm{BC}$ contó con su propio Comité de Biblioteca con sus respectivos subcomités de Colecciones y de Servicios y se redactó también, por primera ocasión, un Manual de Procesos Menores para la BC.

Se fortalecieron los productos electrónicos y las bases existentes CLASE y PERIÓDICA, que alcanzaron más de 200 mil registros cada una. Se realizaron varias ediciones de la Feria del Libro de la Biblioteca Central; prácticamente, todos los años tuvieron lugar eventos culturales como conferencias, exposiciones, presentaciones de libros; actividades que se duplicaron al celebrarse el 45 y el 50 aniversarios de la BC. Así mismo, la labor editorial se despliega con varias publicaciones como el segundo volumen de los Nuevos edificios para las Bibliotecas Universitarias, la Representación Histórica de la Cultura, sobre los murales de Juan O'Gorman, el libro Biblioteca Central. Libros, Muros y Murales. 50 Aniversario de la $B C$; se continúa con la Revista Biblioteca Universitaria y se editaron tres libros de una nueva serie Cuadernos de la DGB: Comprender y vivir la lectura, Introducción a la lectura de la imagen y Los tiempos de Juárez. 
Se llevó a cabo un número sin precedentes de cursos de actualización, capacitación y seminarios y se establecieron nuevas bases para la vinculación externa con el sector público y privado; se amplió la cooperación institucional con prácticamente todas las universidades públicas del país y se invitó a destacados conferencistas internacionales expertos en el campo bibliotecológico.

Los 170 técnicos académicos que conforman la plantilla de la DGB fueron mejorados en sus niveles de nombramientos y en las prestaciones por su desempeño; un buen número se tituló o hizo una maestría. En el Comité Asesor de la DGB por primera vez comenzaron a participar los representantes académicos, así como algunos jefes de departamento.

Se inició el desarrollo de la hemeroteca Scielo México, integrante de la Red Iberoamericana (Scientific Electronic Library on Line), para la difusión de las revistas mexicanas; se apoyó el Programa de Fortalecimiento al Bachillerato y a la licenciatura a través de la participación de la DGB en el Programa de Desarrollo de Habilidades Informativas de la UNAM.

Para 2003 y subsiguientes años continuaron las mejoras al Sistema Bibliotecario y la creación de redes de índole temática: como la Red Eco (de economía) la Red Bios (de ciencias biológicas) y la Red Matemáticas, así como la adecuación, adaptación y remodelación de más bibliotecas, que para 2007 sumaron 139; se incrementó el promedio anual de usuarios asistentes a más de 22 millones y de casi 6 millones de préstamos de libros a domicilio. Sólo la BC atendió al año a casi 3 millones de usuarios ${ }^{27}$ en un horario más amplio todos los días de la semana.

Con las bibliotecas de los subsistemas de bachillerato, licenciatura y posgrado se mantuvo una permanente comunicación -hasta la fecha- con un espíritu de trabajo conjunto, se les ha ido renovando de manera cuantitativa sus equipos de trabajo.

27 Universidad Nacional Autónoma de México. Agenda estadística. México: UnAm, Dirección General de Planeación, Evaluación y Proyectos Académicos,198?-
Con la nueva cifra de bibliotecas se adquirió en el último año señalado 67 mil 677 títulos y 13 mil volúmenes; y el acervo de todas alcanzó la cantidad de 2 millones 485 mil 359 títulos y 6 millones 485 mil 712 volúmenes. Se digitalizaron y se pusieron a consulta 9 mil 286 libros electrónicos, 23 mil 246 revistas electrónicas de texto completo, 232 bases de datos internacionales especializadas. Hubo 3 millones 641 mil 796 consultas a bases de datos y se obtuvieron un millón 995 mil 939 artículos de texto completo en la red. ${ }^{28}$

En los catálogos y bases de datos referenciales (Librunam, TESIUNAM, SERIUNAm y mapameX) los registros llegaron a la cifra de casi 122 mil y los volúmenes a casi 16 millones. ${ }^{29}$

La doctora González Marín falleció el 18 de mayo de 2011. El 1 de septiembre de este mismo año la UNAM, a través de la Coordinación de Humanidades y del Instituto de Investigaciones Bibliográficas, le rindió un homenaje presidido por el doctor José Narro, con la presencia de distinguidos universitarios como el doctor Juan Ramón de la Fuente. En esta ocasión, el rector destacó que Silvia González Marín fue una persona con una trayectoria extraordinaria, gran universitaria, investigadora, profesora y servidora de esta casa de estudios, siempre comprometida con ella...

\section{A 100 años: nuevos retos}

El doctor José Narro Robles fue designado rector por la Junta de Gobierno el 17 de noviembre de 2007. Muchas han sido las acciones que ha llevado a cabo a lo largo de estos cuatro años en pro de la defensa de la autonomía universitaria, su presupuesto y el incremento de un número mayor de estudiantes de nuevo ingreso. Los asuntos nacionales que afectan a toda la sociedad en general no le han sido ajenos, como una parte fundamental de atender a la vez la educación superior y la cultura.

28 Idem.

29 Rojas, Juan Romeo, Hernández Sánchez, Gloria Adriana, Zetter LEAL, Julio, op. cit. 
A Narro le tocó recibir, a nombre de la unam, el Premio Príncipe de Asturias que otorga España a instituciones o personajes distinguidos. Presidió el Comité Internacional de Universia y convocó a más de mil rectores en Guadalajara, Jalisco, en 2010, siendo un fuerte impulsor de la creación del Espacio lberoamericano del Conocimiento, propuesta que ha llevado a muchas instituciones de América Latina. Así mismo, es presidente del Espacio Común de Educación Superior (ECOES) que agrupa a 39 instituciones públicas de enseñanza superior de México y dentro de sus programas cuenta con el de Bibliotecas Digitales, que coordina desde 2006 la DGB, y que ha impulsado la incorporación de centros de enseñanza superior del país a este proyecto; ${ }^{30}$ se han continuado las gestiones iniciales -hoy ya muy avanzadas- para la consolidación de un consorcio de recursos de información científica y tecnológica que incluyen revistas científicas, publicaciones electrónicas y digitales y bases de datos.

En enero de 2008 el rector Narro nombró al doctor Adolfo Rodríguez Gallardo director general de Bibliotecas, cargo que ocupa por tercera ocasión. En las nuevas actividades que asume se ha visto reflejada su experiencia anterior. Es importante destacarlo debido a que una de sus inquietudes, como se precisó líneas arriba, ha sido la preparación de los futuros maestros y responsables del servicio bibliotecario, así como formar teóricos en esta disciplina que continúen el avance de la ciencia bibliotecológica. Una forma de distinguir y alentar el trabajo del personal que se dedica al trabajo bibliotecario es la convocatoria lanzada por tercera vez para otorgar el Premio al Servicio Bibliotecario 2012, instaurado a partir de 2009.

En lo particular, habría que subrayar el empeño de la $\mathrm{DGB}$, en este período, en la construcción de las colecciones digitales, en la extensión de esta actividad por las universidades del país, como compromiso de la UNAM, y su puesta al alcance de las comunidades de estudiantes, profesores e investigadores. Así mismo, romper la brecha digital que separa a la sociedad mexicana (situación en la que todavía se encuentra una gran parte de la población universitaria) entre los que

30 Se pueden consultar las páginas web del ECOES y de la DGB. obtienen los conocimientos por este medio y los que no, así como disminuir el desequilibrio existente de los recursos electrónicos y de su uso.

El desafío del nuevo siglo universitario que viene tendrá que tomar como prioritaria la adecuación de sus espacios y equipos para tener acceso a las fuentes de consulta. Ya no se tratará de seguir construyendo más edificios para albergar las grandes cantidades de impresos en las bibliotecas, sino de dotarlas de equipos para que los usuarios se conecten con el mundo. Otro reto más es seguir con la fusión en redes de algunas bibliotecas, porque manejan la misma área de conocimiento o paralela, como una opción de racionalizar los recursos de la UnAM. El Sistema Bibliotecario tendrá que repensar en estructuras adecuadas $y$, sobre todo, buscar la forma de enfrentar los costos de esta modernización.

Con el afán de dar una perspectiva con la que se cierra este ciclo de la UNAM a sus cien años, la Agenda Estadística de la UNAM 2011 consigna los siguientes datos: bibliotecas 134; material bibliográfico: 2624 149 títulos y 6746758 volúmenes del acervo universitario para dar servicios a 316589 alumnos desde el nivel de bachillerato a posgrado y a 36172 académicos, más los estudiantes de educación continua y el público en general, que también hacen uso de las instalaciones para sus consultas.

En cuanto a sus planes y programas de estudio, la UNAM tiene 40 programas de posgrado con 83 planes de maestría y doctorado y 33 programas de especialización con 193 orientaciones. En licenciatura tiene 91 carreras en 165 planes de estudio y en educación media y superior 3 planes de estudio de bachillerato y 4 carreras técnicas (enfermería y música).

Sus instalaciones están divididas en: 13 facultades, 6 unidades multidisciplinarias y 4 escuelas; en bachillerato son 9 planteles de la Escuela Nacional Preparatoria y 5 planteles del Colegio de Ciencias y Humanidades. Tiene 29 institutos, 16 centros y 8 programas universitarios.

Por subsistemas, las bibliotecas por consiguiente están divididas como sigue: Licenciatura y Posgrado 45; Inves- 
tigación Científica 30; Investigación en Humanidades 21; Bachillerato 16 y Extensión y Administración Universitaria 22, distribuidas en diversas entidades de la República Mexicana y en el extranjero (información estadística del Sistema Bibliotecario de la UNAM 2010). La asistencia de usuarios en 2010 a las bibliotecas SIBIUNAM (como ahora se denomina, Sistema Bibliotecario y de Información de la UNAM) fue de 21409 349. Como anexo, se presenta un cuadro del panorama general bibliotecario 2000-2010.

Por último, no puede soslayarse la labor editorial que ha venido desarrollando la Universidad y de fomento a la lectura como grandes complementos de la aprehensión de saberes y su difusión, en los que las bibliotecas son los recintos principales para su consulta pues en ellas se ha depositado gran parte de la producción de la UNAM.

Con el afán de poner al alcance de todos los interesados la literatura castellana, la UNAM, junto con el Gobierno de España, abrió para consulta en acceso abierto la colección de la "Biblioteca Miguel de Cervantes". En este orden, recientemente se instaló, conjuntamente con el gobierno de la República China, la Biblioteca "Confucio" en uno de los edificios del Centro Histórico, bajo el resguardo del Centro de Enseñanza de Lenguas Extranjeras. Y para la difusión de la cultura e historia de México se cuentan con varias sedes en el extranjero, con sus correspondientes bibliotecas, a cargo del Centro de Estudios para Extranjeros, tanto en Estados Unidos, Canadá y en proceso en algunos países de Europa.
Al igual, recientemente el Consejo Universitario aprobó la sede de la Escuela de Estudios Superiores de León, Guanajuato, como unidad foránea, la cual abrió sus puertas en agosto del presente año para cuatro carreras, con sus respectivas bibliotecas; también creo otro campus en Morelia y otro en San Miguel de Allende. De esta forma la UNAM se ha mantenido a la vanguardia de la creación de nuevas carreras y nuevos programas de estudios que han ido sustituyendo a los ya obsoletos.

A cien años el espíritu de Justo Sierra sigue merodeando entre nosotros, pero ahora también a través de los dispositivos electrónicos de escritorio o de bolsillo, pues las ciudades del conocimiento siguen desarrollándose con enorme celeridad.

En el Centenario de la UNAM al doctor Narro le ha tocado una nueva era de modernidad, que como en el pasado se identifica con las causas sociales que ha asumido la Universidad como su gran compromiso a través de la educación superior.

A José Narro Robles le correspondió encabezar los festejos del primer Centenario de la "Universidad de la Nación" el pasado 22 de septiembre de 2010. Él se ha disculpado porque no podrá asistir a la celebración del bicentenario, pero las bibliotecas tienen registrados estos primeros cien años en cualquier formato y seguirán resguardando los grandes valores del conocimiento del presente y el futuro. os

\section{Obras consultadas}

Biblioteca Nacional: se fundó hace 127 años. Gaceta UNAM, 31 de marzo de 2011.

Biblioteca Universitaria: revista de la Dirección General de Bibliotecas. - nueva época vol. I, no. 1, (ene-jun. 1998) - . -- México: unam, Dirección General de Bibliotecas, 1986- . v.

Biblioteca Universitaria: revista de la Dirección General de Bibliotecas [en línea]. - nueva época vol. I, no. 1, (ene-jun.
1998) - . -- México: unAM, Dirección General de Bibliotecas, 1986- . < http://revistas.unam.mx/index.php/rbu>

Los 100 años de la UNAM. Coordinación Elena Gallegos. México: La Jornada, 2010. 278 p.

Cincuenta años de estudios universitarios en bibliotecología: una revisión de su historia. Judith Licea de Arenas, coordinadora. México: Sistemas Biblioinforma, 2007. 
Enciclo: lista de distribución de los usuarios de la Enciclopedia Libre.<enciclo@listas.us.es>

Gaceta UNAM [en línea]. <http://www.dgcs.unam.mx/ gacetaweb/>

Garciadiego Dantán, Javier. De Justo Sierra a Vasconcelos: la Universidad Nacional durante la Revolución mexicana. México: El Colegio de México, 1996. HM, xLvı: 4.

El libro de texto en la era digital. Revista Transatlántica de Educación, no. 7, 2009.

Nuevos edificios para las bibliotecas universitarias. Coordinador general Adolfo Rodríguez Gallardo. México: UNAM, Dirección General de Bibliotecas, 1996. 174 p.

Rodríguez Gallardo, Adolfo. La Biblioteca Central y las bibliotecas de la unAm. Revista Universidad de México, 1996.

El personal bibliotecario académico de la Universidad. En: Universidad Nacional Autónoma de México. Dirección General de Bibliotecas. Biblioteca Central: libros, muros y murales, 50 Aniversario. Editado por Celia Martín Marín. México: unAM, Dirección General de Bibliotecas, 2006, p. 229-235.

--------. Semblanza de la doctora Silvia González Marín, en ocasión de su homenaje póstumo. [Documento interno].

Rojas, Juan Romeo, Hernández SÁnchez, Gloria Adriana, Zetter Leal, Julio. Destino y vocación: biblioteca universitaria. En: Universidad Nacional Autónoma de México. Dirección General de Bibliotecas. Biblioteca Central: libros, muros y murales, 50 Aniversario. Editado por Celia Martín Marín. México: unAM, Dirección General de Bibliotecas, 2006, p. 173-197.

Sametz de Walerstein, Linda. Vasconcelos, el hombre del libro: creador del primer sistema de bibliotecas. México: CONACULTA, 2009. 128 p.
Torre Revello, José. Lecturas Indianas: siglos XVI-XviII. Bogotá, 1962. Separata de Thesaurus, Boletín del Instituto Caro y Cuervo, xvir, 1962. En: Millares Carlo, Agustín. Introducción a la Historia del libro y las bibliotecas. México: Fondo de Cultura Económica, 1988. 394 p.

Torres Vargas, Georgina Araceli. La biblioteca digital. México: unam, Centro Universitario de Investigaciones Bibliotecológicas, 2005. 69 p.

Universidad Nacional Autónoma de México [en línea]. <http://www.unam.mx/>

Universidad Nacional Autónoma de México. Agenda estadística. México: unam, Dirección General de Planeación, Evaluación y Proyectos Académicos, 198?-

Universidad Nacional Autónoma de México. Centro Universitario de Investigaciones Bibliotecológicas [en línea]. <http://cuib.laborales.unam.mx/>

Universidad Nacional Autónoma de México. Dirección General de Bibliotecas [en línea]. <http://dgb.unam.mx/>

Universidad Nacional Autónoma de México. Dirección General de Bibliotecas. Biblioteca Central: libros, muros y murales, 50 Aniversario. Editado por Celia Martín Marín. México: unAM, Dirección General de Bibliotecas, 2006. 255 p.

Reglamento de la Dirección General de Bibliotecas de la Universidad Nacional de México [en línea]. <http://www.abogadogeneral.unam.mx/PDFS/ COMPENDIO/54.pdf>

Universidad Nacional Autónoma de México. Reglamento del Sistema Bibliotecario de la Universidad Nacional Autónoma de México [en línea]. <http://info4. juridicas.unam.mx/unijus/unv/37/>

Universidad Nacional Autónoma de México. Reglamento para las Bibliotecas Universitarias [en línea]. <http://www.abogadogeneral.unam.mx/PDFS/ COMPENDIO/32.pdf> 


\section{Anexo}

UNAM. Servicios bibliotecarios 2000 - 2010

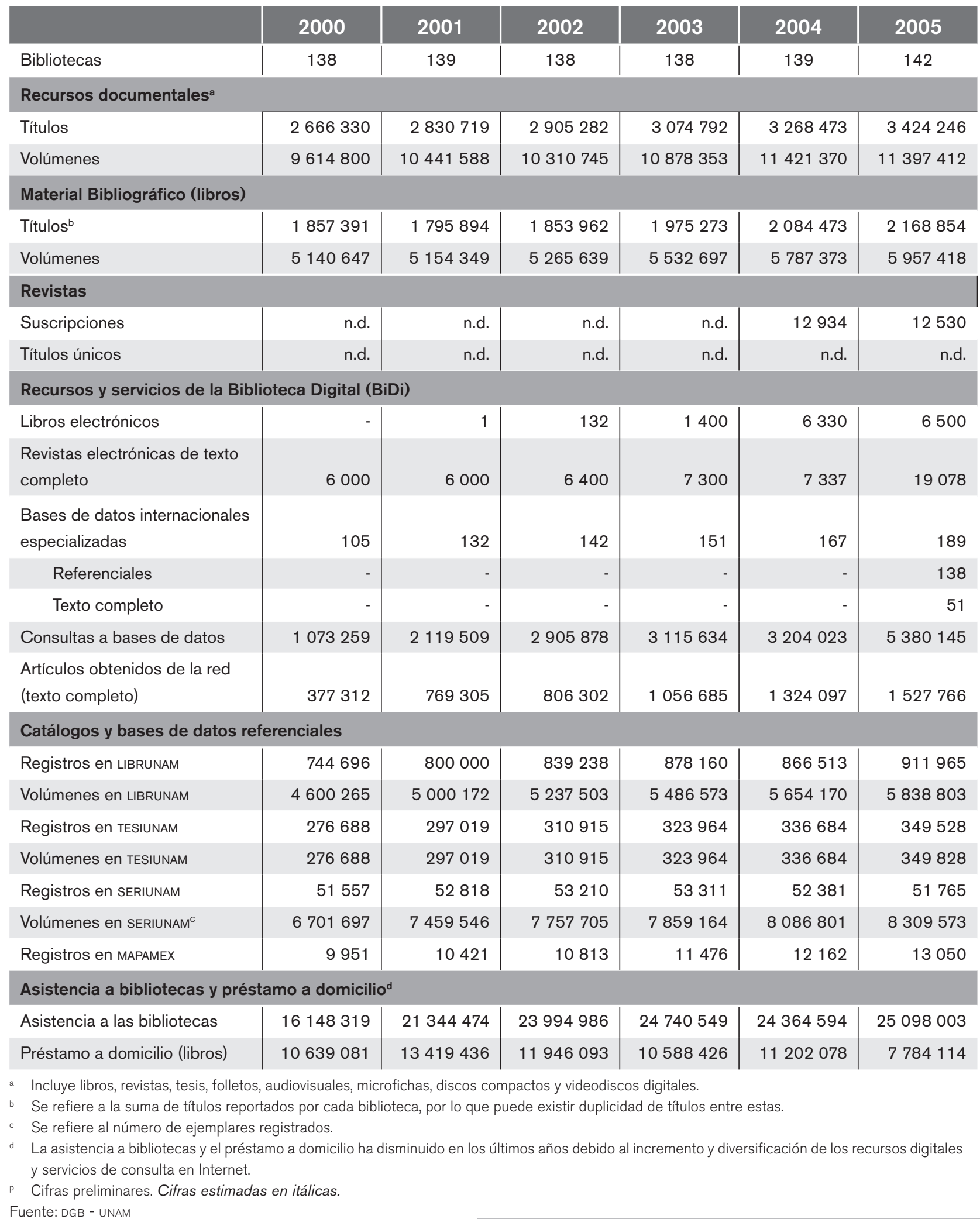




\begin{tabular}{|c|c|c|c|c|c|}
\hline & 2006 & 2007 & 2008 & 2009 & 2010 \\
\hline Bibliotecas & 142 & 141 & 139 & 139 & 134 \\
\hline \multicolumn{6}{|l|}{ Recursos documentales } \\
\hline Títulos & 3718534 & 3949054 & 4092244 & 4481042 & 4480962 \\
\hline Volúmenes & 11529131 & 12129494 & 12987083 & 13073646 & 12887677 \\
\hline \multicolumn{6}{|l|}{ Material Bibliográfico (libros) } \\
\hline Títulos $^{b}$ & 2262796 & 2404110 & 2485359 & 2554883 & 2624149 \\
\hline Volúmenes & 6140043 & 6395569 & 6485712 & 6597337 & 6746758 \\
\hline \multicolumn{6}{|l|}{ Revistas } \\
\hline Suscripciones & 12246 & 12515 & 11945 & 11653 & 11309 \\
\hline Títulos únicos & n.d. & 7512 & 7264 & 7368 & 7147 \\
\hline \multicolumn{6}{|c|}{ Recursos y servicios de la Biblioteca Digital (BiDi) } \\
\hline Libros electrónicos & 7175 & 9286 & 9936 & 8688 & 11544 \\
\hline $\begin{array}{l}\text { Revistas electrónicas de texto } \\
\text { completo }\end{array}$ & 19266 & 23246 & 25848 & 25848 & 26571 \\
\hline $\begin{array}{l}\text { Bases de datos internacionale } \\
\text { especializadas }\end{array}$ & 230 & 232 & 172 & 152 & 155 \\
\hline Referenciales & 114 & 166 & 112 & 94 & 104 \\
\hline Texto completo & 116 & 66 & 60 & 58 & 51 \\
\hline Consultas a bases de datos & 4532376 & 3641796 & 4000000 & 3847619 & 5200000 \\
\hline $\begin{array}{l}\text { Artículos obtenidos de la red } \\
\text { (texto completo) }\end{array}$ & 1708119 & 1995939 & 2200000 & 3480179 & 4500000 \\
\hline \multicolumn{6}{|c|}{ Catálogos y bases de datos referenciales } \\
\hline Registros en LIBRUNAM & 948568 & 948927 & 1024597 & 1059852 & 1097721 \\
\hline Volúmenes en LIBRUNAM & 5990622 & 6132412 & 6220341 & 6348592 & 6412023 \\
\hline Registros en TESIUNAM & 351359 & 371930 & 387159 & 403190 & 415168 \\
\hline Volúmenes en TESIUNAM & 351359 & 371930 & 497483 & 508638 & 519164 \\
\hline Registros en SERIUNAM & 51697 & 51146 & 52723 & 55041 & 61400 \\
\hline Volúmenes en SERIUNAM ${ }^{C}$ & 8462552 & 8707743 & 9007914 & 9235442 & 9679706 \\
\hline Registros en MAPAMEX & 13389 & 13548 & 14063 & 18164 & 21691 \\
\hline \multicolumn{6}{|c|}{ Asistencia a bibliotecas y préstamo a domicilio ${ }^{d}$} \\
\hline Asistencia a las bibliotecas & 23009213 & 21871494 & 19270283 & 21271589 & 21409349 \\
\hline Préstamo a domicilio (libros) & 6772252 & 5606887 & 5037327 & 5315645 & 4375970 \\
\hline
\end{tabular}

\section{4}

